\title{
Comparative study of safety and efficacy of intravenous iron sucrose and ferric carboxymaltose in the treatment of postpartum iron deficiency anaemia
}

\author{
Alpana Singh*, Ramadevi Yerragudi
}

Department of Obstetrics \& Gynaecology, Malla Reddy Institute Of Medical Sciences, Hyderabad, Telangana, India

Received: 02 February 2016

Accepted: 01 March 2016

\section{*Correspondence:}

Dr. Alpana Singh,

E-mail: dralpanasingh21@gmail.com

Copyright: $\odot$ the author(s), publisher and licensee Medip Academy. This is an open-access article distributed under the terms of the Creative Commons Attribution Non-Commercial License, which permits unrestricted non-commercial use, distribution, and reproduction in any medium, provided the original work is properly cited.

\begin{abstract}
Background: Anaemia is the most commonly encountered and reversible medical problem during pregnancy and postpartum period. It adversely affects the health of both mother and foetus. Oral iron therapy has many disadvantages-poor compliance and gastrointestinal side effects lead the list. Intravenous iron is an effective alternative in correcting anaemia and restoring iron stores. The objective of this study was to evaluate the safety and efficacy of intravenous iron sucrose and ferric carboxymaltose in treatment of post partum anaemia and compare the rise in $\mathrm{Hb} \%$ and serum ferritin stores after treatment with IV iron sucrose and ferric carboxymaltose.

Methods: This was a prospective analytical study conducted on 100 postpartum patients in a medical college and research centre in South India. Patients for study were selected from the postnatal ward, having haemoglobin concentration of $<10 \mathrm{gm} / \mathrm{dl}$ and iron deficiency anaemia as the aetiology. All the selected patients were randomly categorized into two groups to receive intravenous iron sucrose and ferric carboxymaltose. The tolerability and side effects of both the injections were noted. $\mathrm{Hb} \%$ and serum ferritin were repeated 2 weeks and 6 weeks after treatment and results analyzed.

Results: The increment in $\mathrm{Hb} \%$ in IV iron sucrose group after 2 and 6 weeks was $9.69 \pm 0.49 \mathrm{gm} / \mathrm{dl}$ and $11.28 \pm 0.53$ $\mathrm{gm} / \mathrm{dl}$ respectively. Ferric carboxymaltose showed $9.8 \pm 0.43 \mathrm{gm} / \mathrm{dl}$ and $12.22 \pm 0.43 \mathrm{gm} / \mathrm{dl}$ rise in $\mathrm{Hb} \%$ at the same time interval. Serum ferritin showed a significant increase in IV ferric carboxymaltose group as compared to IV iron sucrose at 2 and 6 weeks ( $\mathrm{p}=0.049 ; \mathrm{p}=0.023)$.

Conclusions: Ferric carboxymaltose has a greater safety profile (p) and offers faster elevation of haemoglobin and iron stores with lesser hospital stay as compared to iron sucrose.
\end{abstract}

Keywords: Iron sucrose, Ferric carboxymaltose, Postpartum anaemia, Haemoglobin, Ferritin

\section{INTRODUCTION}

Anaemia is most commonly encountered and easily reversible health problem during pregnancy and postpartum period. It is a major cause of concern as besides many adverse effects on mother and foetus, it contributes significantly to high maternal mortality and morbidity. The most common cause of anaemia during child bearing period is iron deficiency. ${ }^{1}$ Iron nutritional status depends on long term iron balance -ingestion of adequate amount of iron in the diet and its absorption from the gut vis-à-vis consumption/loss in conditions of overt or covert blood loss and removal of old and effete red blood cells. Iron deficiency may result from inadequate dietary intake, achlorhydria or excessive ingestion of proton pump inhibitors, parasitic infestations, chronic infections and repeated pregnancies. Iron supplementation of antenatal patients is a basic tenet of 
antenatal care programmes in numerous developing and underdeveloped nations.

Postpartum anaemia is defined as haemoglobin of less than 10 gm\% during the postpartum period. ${ }^{2}$ The prevalence of postpartum anaemia varies from $4-27 \%{ }^{3}$ Chronic iron deficiency due to inadequate intake/ lack of iron supplementation during pregnancy, repeated pregnancies and postpartum haemorrhage are important causes of postpartum anaemia. Postpartum anaemia is associated with anxiety, depression and prolonged hospital stay. It imposes a substantial disease burden during the critical period of maternal - infant interaction and may give rise to lasting developmental deficits in infant of affected mothers. ${ }^{4}$

The standard treatment of postpartum anaemia is oral iron supplementation with blood transfusion reserved for severe anaemia. Treatment with high doses of oral iron has poor compliance and produces lot of side effects including gastric irritation, nausea, diarrhoea and constipation. Parenteral iron scores over oral therapy by providing a faster and more effective correction of total iron deficit sans gastrointestinal side effects.

Two types of intravenous (IV) preparations available are IV iron sucrose and IV ferric carboxymaltose. IV iron sucrose is safe, effective and economical. Reported incidence of adverse reactions with IV iron sucrose is less as compared to older iron preparations(Iron dextran, iron sorbitol), but it requires multiple doses and prolonged infusion time. ${ }^{5}$ Ferric carboxymaltose is a dextran free iron formulation, has neutral $\mathrm{pH}$ and physiological osmolarity. It can be administered in high single dose without the risk of severe anaphylactic reactions. ${ }^{6}$ In our study, we compare the tolerability and efficacy of IV iron sucrose and IV ferric carboxymaltose in treatment of postpartum iron deficiency anaemia.

\section{METHODS}

This was a prospective analytical study conducted on 100 postpartum patients in a tertiary hospital from November 2014 to October 2015. Approval from the ethics committee was obtained before starting the study. Patients for study were selected from the postnatal ward, having haemoglobin concentration of $<10 \mathrm{gm} / \mathrm{dl}$. Patients with haemolytic disorders, megaloblastic anaemia, aplastic anaemia, previous surgeries of intestinal resections/bypass, chronic renal disease, liver disease were excluded from the study. After careful history taking and examinations, a complete blood picture, serum Ferritin and peripheral smear were done to diagnose iron deficiency anaemia. Those with $\mathrm{Hb} \% \leq 6 \mathrm{gm} / \mathrm{dl}$ were considered for blood transfusion. All the selected patients having iron deficiency anaemia were randomly categorized into two groups to receive intravenous iron sucrose and ferric carboxymaltose. Required doses of iron was calculated by the following formula -
$2.21 \times$ body weight in $\mathrm{kg} \times \mathrm{Hb}$ deficit +500 ( $\mathrm{Hb}$ deficit $=$ Target $\mathrm{Hb}-$ actual $\mathrm{Hb}$ )

Target $\mathrm{Hb} \%$ in postpartum women taken was $12 \mathrm{~g} / \mathrm{dl}$; $500 \mathrm{mg}$ is for body stores.

Iron sucrose was given as intravenous infusion of $200 \mathrm{mg}$ of elemental iron diluted in $100 \mathrm{ml}$ of $0.9 \%$ normal saline over 30 minutes, repeated on alternate day.

Ferric carboxymaltose was administered as intravenous infusion of maximum single dose of $1000 \mathrm{mg}$ diluted in $250 \mathrm{ml}$ of $0.9 \%$ normal saline over 15 to 30 minutes. Dose was repeated after 1 week if required.

The tolerability and side effects of both the injections were noted. $\mathrm{Hb} \%$ and serum ferritin were repeated 2 weeks and 6 weeks after treatment and analyzed.

\section{Statistical analysis}

Statistical testing was conducted with the statistical package for the social science system (SPSS). Categorical variables are presented as absolute numbers and percentage. Nominal categorical data between the groups were compared using chi2 goodness-to-fit test. The $\alpha$ level was set as $\mathrm{p}$ value less than 0.05 .

\section{RESULTS}

In our prospective study, 100 postpartum patients with iron deficiency anaemia were randomized to receive IV iron sucrose (group 1) or IV ferric carboxymaltose (group $2)$. Table 1 shows the baseline characteristics of the patients in both the groups. The mean age and mean weight of the patients in iron sucrose group were $23.74 \pm 3.94$ years and $54.10 \pm 7.32 \mathrm{Kg}$ while $23 \pm 4.21$ years and $54.8 \pm 6.91 \mathrm{Kg}$ in ferric carboxymaltose group respectively. Other demographic data like parity and mode of delivery were compared which were found to be clinically insignificant. Baseline haemoglobin concentration, serum ferritin level and total iron deficits were comparable in the two groups.

As shown in Table 2, adverse reactions were milder in both the groups. None of the patients in two groups had severe anaphylactic reactions. Adverse reactions noted were local reactions (swelling, erythema and burning at injection site), vomiting, giddiness and fever. Rate of adverse reaction was $18 \%$ in IV iron sucrose group as compared to $6 \%$ in ferric carboxymaltose group $(\mathrm{p}=0.00035)$.

There was an overall rise in $\mathrm{Hb} \%$ and serum ferritin level from baseline in both the treatment modalities after 2 and 6 weeks of therapy (Table 3). After 2 weeks the mean $\mathrm{Hb} \%$ increment was similar in two groups $(9.69 \pm 0.49$ with IV iron sucrose versus $9.80 \pm 0.43$ with IV ferric carboxymaltose, $\mathrm{p}=0.96$ ). But the increment in $\mathrm{Hb} \%$ with IV ferric carboxymaltose was more than IV iron 
sucrose after 6 weeks although statistically insignificant (11.28 \pm 0.53 versus $12.22 \pm 0.43 ; p=0.78)$

Serum ferritin also showed significant increment after 2 and 6 weeks of therapy in both the modalities and increment was more in IV ferric carboxymaltose group ( $\mathrm{p}$ $=0.049 ; \mathrm{p}=0.023$ ).

Table 1: Baseline characteristics of patients in two groups.

\begin{tabular}{|lll|}
\hline Parameters & $\begin{array}{l}\text { Iron sucrose } \\
\mathbf{N}=50\end{array}$ & $\begin{array}{l}\text { Ferric } \\
\text { carboxymaltose } \\
\text { N=50 }\end{array}$ \\
\hline Mean age & $23.74 \pm 3.94$ & $23 \pm 4.21$ years \\
\hline Mean weight & $54.10 \pm 7.32 \mathrm{Kg}$ & $54.8 \pm 6.91 \mathrm{Kg}$ \\
\hline Parity & & \\
\hline Primi & $22(44 \%)$ & $24(48 \%)$ \\
\hline Multi & $28(56 \%)$ & $26(52 \%)$ \\
\hline Type of delivery & & \\
\hline Vaginal delivery & $32(64 \%)$ & $29(58 \%)$ \\
\hline LSCS & $18(36 \%)$ & $21(42 \%)$ \\
\hline History of PPH & $2(4 \%)$ & $3(6 \%)$ \\
\hline Base line Hb\% & $7.98 \pm 0.78 \mathrm{gm} / \mathrm{dl}$ & $7.88 \pm 0.76 \mathrm{gm} / \mathrm{dl}$ \\
\hline Base line ferritin & $13.6 \pm 3.08 \mathrm{ng} / \mathrm{ml}$ & $14.46 \pm 2.64 \mathrm{ng} / \mathrm{ml}$ \\
\hline Total iron deficit & $980.72 \pm 120.33 \mathrm{mg}$ & $988.38 \pm 103.61 \mathrm{mg}$ \\
\hline
\end{tabular}

Table 2: Comparison of adverse effects in both the groups.

\begin{tabular}{|lllll|}
\hline \multirow{2}{*}{$\begin{array}{l}\text { Adverse effects } \\
\text { Sucrose } \\
\text { N=50 }\end{array}$} & $\begin{array}{l}\text { Ferric } \\
\text { carboxymaltose } \\
\text { N=50 }\end{array}$ \\
\hline Local reactions & $\mathbf{N}$ & $\mathbf{\%}$ & $\mathbf{N}$ & $\mathbf{\%}$ \\
\hline Rashes & 2 & $4 \%$ & 1 & $2 \%$ \\
\hline Vomiting & 0 & 0 & 0 & 0 \\
\hline Giddiness/hypotension & 2 & $4 \%$ & 0 & 0 \\
\hline Fever & 3 & $6 \%$ & 1 & $2 \%$ \\
\hline Breathlessness & 2 & $4 \%$ & 1 & $2 \%$ \\
\hline Total & 0 & 0 & 0 & 0 \\
\hline
\end{tabular}

Table 3: Comparison of change in haematological parameters after therapy in both groups.

\begin{tabular}{|llll|}
\hline Parameters & $\begin{array}{l}\text { Iron } \\
\text { sucrose }\end{array}$ & $\begin{array}{l}\text { Ferric } \\
\text { carboxymaltose }\end{array}$ & $\begin{array}{l}\text { P } \\
\text { value }\end{array}$ \\
\hline Haemoglobin & $\mathrm{gm} / \mathrm{dl}$ & $\mathrm{gm} / \mathrm{dl}$ & \\
\hline Base line & $7.98 \pm 0.78$ & $7.88 \pm 0.76$ & \\
\hline 2 weeks & $9.69 \pm 0.49$ & $9.80 \pm 0.43$ & 0.96 \\
\hline 6 weeks & $11.28 \pm 0.53$ & $12.22 \pm 0.43$ & 0.78 \\
\hline Serum ferritin & $\mathrm{ng} / \mathrm{ml}$ & $\mathrm{ng} / \mathrm{ml}$ & \\
\hline Base line & $13.6 \pm 3.05$ & $14.54 \pm 2.46$ & \\
\hline 2 weeks & $37.54 \pm 3.82$ & $51.56 \pm 2.80$ & 0.049 \\
\hline 6 weeks & $52.86 \pm 10.06$ & $72 \pm 12.14$ & 0.023 \\
\hline
\end{tabular}

\section{DISCUSSION}

Iron deficiency anaemia during postpartum period is common and deserves special attention due to its potential adverse consequences. It imposes a substantial disease burden during the critical period of maternal infant interactions. Oral iron therapy is the standard therapy for postpartum iron deficiency anaemia but has poor compliance and tolerance due to its gastrointestinal side effects. Though blood transfusion gives faster recovery, its availability is limited and is associated with serious transfusion reactions and high risk of infections like hepatitis B, C and HIV( although remote). Thus blood transfusions are reserved for the most severe and life threatening situations. ${ }^{7}$ Parental iron therapy in this setting seems to be a good and safe alternative.

Present study showed that iron sucrose complex as well as ferric carboxymaltose can be used for correction of postpartum anaemia and restoration of iron stores.

Our study showed that the rise in $\mathrm{Hb} \%$ and serum ferritin levels was considerable in both the treatment modalities and it was more with ferric carboxymaltose. Similar results were reported by Patel $\mathrm{J}$ et al in their study comparing intravenous iron sucrose and intravenous ferric carboxymaltose therapy in iron deficiency anaemia during pregnancy and postpartum period. ${ }^{8}$ In another comparative study by Rathod S et al 300 postpartum patients received oral iron, iron sucrose or ferric carboxymaltose for correction of anaemia. ${ }^{9}$ Ferric carboxymaltose was found superior to oral iron and iron sucrose in raising haemoglobin and serum ferritin.

Our study shows that both the treatment modalities are well tolerated in postpartum patients. In both the groups the adverse reactions were mild and quickly reversible; although statistically significant reactions were more with IV iron sucrose. There were neither any treatment related severe adverse events nor any serious anaphylactic reaction in both the groups. A similar retrospective observational study was done by Pfenniger A et al to compare the safety and efficacy of intravenous high dose of ferric carboxymaltose and iron sucrose for the treatment of postpartum anaemia. ${ }^{10}$ Ferric carboxymaltose was as safe as iron sucrose in the management of postpartum anaemia despite five times of higher doses.

Our study shows that even though administered in high doses, ferric carboxymaltose is well tolerated and more effective than iron sucrose for treatment of post partum iron deficiency anaemia. Compared to iron sucrose, it offers the advantages of administration of high dose of iron at a time, avoids the need of repeated injections, reduces the duration of hospital stay and increases patient comfort. 


\section{CONCLUSION}

Intravenous ferric carboxymaltose is more effective than intravenous iron sucrose for the correction of postpartum iron deficiency anaemia. It is well tolerated and safe. It should be offered to all postpartum anaemic women to decrease maternal mortality and morbidity.

Funding: No funding sources

Conflict of interest: None declared

Ethical approval: The study was approved by the Institutional Ethics Committee

\section{REFERENCES}

1. Centre for disease control. Criteria for anaemia in children and childbearing aged women. MMWR. 1989;38:400-4.

2. Pavord S, Myers B, Robinson S, Allard S, Strong J, Oppenheimer $\mathrm{C}$, et al. UK guidelines on the management of iron deficiency in pregnancy. $\mathrm{Br} \mathrm{J}$ Haematol. 2012;156:588-600.

3. Kouser S, Kouser S, Malik M, Malik A. Safety and efficacy of intravenous iron therapy in postnatal patients with iron deficiency anemia. J South Asian Fed Obstet Gynaecol. 2011;3(1):25-7.

4. Perez EM, Hendricks MK, Beard JL, Murray-Kolb LE, Berg A, Tomlinson M, et al. Mother-infant interactions and infant development are altered by maternal iron deficiency anemia. J Nutr. 2005;135:850-5.
5. Seid MH, Derman RJ, Baker JB, Banach W, Goldberg C, Rogers R. Ferric carboxymaltose injection in the treatment of postpartum iron deficiency anemia: A randomized controlled clinical trial. Am J Obstet Gynecol. 2008;199:435.e1-7.

6. Breymann C, Gliga F, Bejenariu C, Strizhova N. Comparative efficacy and safety of intravenous ferric carboxymaltose in the treatment of postpartum iron deficiency anemia. Int J Gynaecol Obstet. 2008; 101:67-73.

7. Breymann C. The Use of Iron Sucrose complex for Anemia in Pregnancy and postpartum period. Semin Hematol. 2006;43(Suppl 6):S28-31.

8. Patel J, Patel K, Sharma A, Date SK. Comparison of intravenous Iron sucrose and intravenous Ferric carboxymaltose therapy in iron deficiency anemia during pregnancy and postpartum period. $\mathrm{J}$ of Pharmaceutical science and Bioscientific research. 2015;5(3):239-43.

9. Rathod S, Samal SK, Mahapatra PC, Samal S. Ferric carboxymaltose: A revolution in the treatment of postpartum anemia in Indian women. Int $\mathrm{J}$ Appl Basic Med Res. 2015;5(1):25-30.

10. Pfenniger A, Schuller C, Christoph P, Surbek D. Safety and efficacy of high- dose intravenous iron carboxymaltose vs. Iron sucrose for treatment of postpartum anemia. J Perinat Med. 2012;40(4):397 402.

Cite this article as: Singh $\mathrm{A}$, Yerragudi $\mathrm{R}$. Comparative study of safety and efficacy of intravenous iron sucrose and ferric carboxymaltose in the treatment of postpartum iron deficiency anaemia. Int J Reprod Contracept Obstet Gynecol 2016;5:1130-3. 